\title{
Connecting possibilistic prudence and optimal saving
}

\author{
Ana María Lucia Casademunt ${ }^{1}$ and Irina Georgescu ${ }^{2}$ \\ ${ }^{1}$ University Loyola, Córdoba, Spain \\ ${ }^{2}$ Academy of Economic Studies, Bucharest, Romania
}

\begin{abstract}
In this paper we study the optimal saving problem in the framework of possibility theory. The notion of possibilistic precautionary saving is introduced as a measure of the way the presence of possibilistic risk (represented by a fuzzy number) influences a consumer in establishing the level of optimal saving. The notion of prudence of an agent in the face of possibilistic risk is defined and the equivalence between the prudence condition and a positive possibilistic precautionary saving is proved. Some relations between possibilistic risk aversion, prudence and possibilistic precautionary saving were established.
\end{abstract}

Keywords - Possibility theory, Precautionary saving, Prudence

\section{INTRODUCTION}

$\mathrm{T}$ HE effect of risk on saving was studied for the first time by Leland [1], Sandmo [2] and Drèze and Modigliani [3]. They showed that if the third derivative of the utility function is positive, then the precautionary saving is positive. Kimball introduced in [4] the notion of "prudence" and established its relation with optimal saving.

This paper aims to approach optimal saving and prudence in the context of Zadeh's possibility theory [5]. The first contribution of this paper is a model of optimal saving, similar to the one in [4] or [6], p. 95. The notion of possibilistic precautionary saving (associated with a weighting function $\mathrm{f}$, a fuzzy number A representing the risk and a utility function representing the consumer) is introduced and necessary and sufficient conditions for its positivity are established. The second contribution is the definition of the notion of prudence in possibilistic sense and its characterization in terms of possibilistic optimal saving. The third contribution refers to some relations between the degree of absolute prudence [4], possibilistic risk aversion [7] and possibilistic precautionary saving. Among others, the possibilistic precautionary premium is defined as a possibilistic measure of precautionary motive.

This notion is analogous to (probabilistic) precautionary premium of [4].

We will survey the content of the paper. In Section 2 are recalled, according to [8], [9], [10] the definition of fuzzy numbers and some associated indicators: possibilistic expected utility, possibilistic expected value and possibilistic variance. The equivalence between the concavity (resp. convexity) of a continuous utility function and a possibilistic Jensen-type inequality is proved.

In Section 3 the possibilistic two-period model of precautionary saving is studied. The consumer is represented by two utility functions $\mathrm{u}$ and $\mathrm{v}$ and the risk, present in the second period, is described by a fuzzy number. The expected lifetime utility of the model is defined with the help of the notion of possibilistic expected utility. The main introduced notion is possibilistic precautionary saving. It measures the changes on optimal saving produced by the presence of risk in the second period. If this indicator has a positive value then by adding the risk the consumer will choose a greater level of optimal saving. The main result of the section characterizes the positivity of possibilistic precautionary saving by the condition $v^{\prime \prime \prime}>0$. One also proves an approximate calculation formula of possibilistic precautionary saving.

In Section 4 the notion of prudence of an agent in the face of risk situation is described by a fuzzy number. The definition of this notion follows the line of [11], [12], where we find a "formal" presentation of probabilistic prudence. The main result of the section is a theorem which characterizes possibilistic prudence in terms of the previously studied optimal saving model.

Section 5 begins by recalling the Arrow-Pratt index [13], [14], the degree of absolute prudence [4] and posibilistic risk premium [7]. A result of the section characterizes the property of possibilistic risk premium to be decreasing in wealth by the comparison between prudence and absolute risk aversion (prudence is larger than absolute risk aversion). Then the notion of possibilistic precautionary premium is introduced and some of its properties which establish relations between prudence, possibilistic risk aversion and possibilistic precautionary saving are proved.

The paper ends with a section of concluding remarks.

\section{POSSIBILISTIC EXPECTED UTILITY}

Fuzzy numbers are the most studied class of possibility distributions [10]. Their indicators - the expected value and variance represent the main instrument in the possibilistic study of risk phenomena [7], [9].

In this section we will define the fuzzy numbers and their indicators and we will prove a characterization theorem of convex (resp. concave) functions by possibilistic Jensen-type inequalities. 
Let $\mathrm{X}$ be a non-empty set. A fuzzy subset of X (shortly, fuzzy set) is a function $A: X \rightarrow[0,1]$. A fuzzy set $A$ is normal if $\mathrm{A}(\mathrm{x})=1$ for some $\mathrm{x} \in \mathrm{X}$. The support of $\mathrm{A}$ is defined by $\operatorname{supp}(\mathrm{A})=\{\mathrm{x} \in \mathbf{R} \mid \mathrm{A}(\mathrm{x})>0\}$.

Assume $\mathrm{X}=\mathbf{R}$. For $\gamma \in[0,1]$, the $\gamma$-level set $[A]^{\gamma}$ is defined by

$$
[A]^{\gamma}=\left\{\begin{array}{l}
\{x \in R \mid A(x) \geq \gamma \text { if } \gamma>0 \\
c l(\sup p(A)) \text { if } \gamma=0
\end{array}\right.
$$

$(\operatorname{cl}(\operatorname{supp}(\mathrm{A}))$ is the topological closure of $\operatorname{supp}(\mathrm{A})$.

The fuzzy set $\mathrm{A}$ is fuzzy convex if $[A]^{\gamma}$ is a convex subset of $\mathbf{R}$ for all $\gamma \in[0,1]$. A fuzzy set $\mathbf{A}$ of $\mathbf{R}$ is a fuzzy number if it is normal, fuzzy convex, continuous and with bounded support. If $\mathrm{A}, \mathrm{B}$ are fuzzy numbers and $\lambda \in \mathbf{R}$ then the fuzzy numbers $\mathrm{A}+\mathrm{B}$ and $\lambda \mathrm{A}$ are defined by

$$
\begin{aligned}
& (A+B)(x)=\sup _{y+z=x} \min (A(y), B(z)) \\
& (\lambda A)(x)=\sup _{\lambda y=x} A(y)
\end{aligned}
$$

A non-negative and monotone increasing function $\mathrm{f}:[0,1] \rightarrow \mathbf{R}$ is a weighting function if it satisfies the normality condition $\int_{0}^{1} f(\gamma) d \gamma=1$.

Let $f$ be a weighting function and $u: R \rightarrow R$ a continuous utility function. Assume that $\mathrm{A}$ is a fuzzy number whose level sets have the form $[A]^{\gamma}=\left[a_{1}(\gamma), a_{2}(\gamma)\right]$ for any $\gamma \in[0,1]$.

The possibilistic expected utility $\mathrm{E}(\mathrm{f}, \mathrm{u}(\mathrm{A}))$ is defined by:

$$
E(f, u(A))=\frac{1}{2} \int_{0}^{1}\left[u\left(a_{1}(\gamma)\right)+u\left(a_{2}(\gamma)\right)\right] f(\gamma) d \gamma
$$

If $u$ is the identity function of $\mathbf{R}$ then $E(f, u(A))$ is the possibilistic expected value [9]:

$$
E(f, A)=\frac{1}{2} \int_{0}^{1}\left[a_{1}(\gamma)+a_{2}(\gamma)\right] f(\gamma) d \gamma
$$

If $u(x)=(x-E(f, A))^{2}$ for any $\mathrm{x} \in \mathbf{R}$ then $\mathrm{E}(\mathrm{f}, \mathrm{u}(\mathrm{A}))$ is the possibilistic variance [9]:

$$
\begin{aligned}
& \operatorname{Var}(f, A)=\frac{1}{2} \int_{0}^{1}\left[\left(a_{1}(\gamma)-E(f, A)\right)^{2}+\right. \\
& \left.+\left(a_{2}(\gamma)-E(f, A)\right)^{2}\right] f(\gamma) d \gamma
\end{aligned}
$$

When $\mathrm{f}(\gamma)=2 \gamma, \gamma \in[0,1], \mathrm{E}(\mathrm{f}, \mathrm{A})$ and $\operatorname{Var}(\mathrm{f}, \mathrm{A})$ are the notions introduced by Carlsson and Fullér in [8].

Proposition 1. [7] Let $g, h$ be two utility functions and a, $\mathrm{b} \in \mathbf{R}$. If $\mathrm{u}=\mathrm{ag}+\mathrm{bh}$ then $\mathrm{E}(\mathrm{f}, \mathrm{u}(\mathrm{A}))=\mathrm{aE}(\mathrm{f}, \mathrm{g}(\mathrm{A}))+\mathrm{bE}(\mathrm{f}, \mathrm{h}(\mathrm{A}))$.

Lemma 1. [15] Let $u: R \rightarrow R$ be a continuous utility function. The following are equivalent:

a) $u$ is concave; b) For any a, beR, $\frac{u(a)+u(b)}{2} \leq u\left(\frac{a+b}{2}\right)$.

Proposition 2. If $\mathrm{u}$ is a continuous utility function then the following are equivalent:

(i) $\mathrm{u}$ is concave;

(ii) $\mathrm{E}(\mathrm{f}, \mathrm{u}(\mathrm{A})) \leq \mathrm{u}(\mathrm{E}(\mathrm{f}, \mathrm{A}))$ for any fuzzy number $\mathrm{A}$.

Proof. (i) $\Rightarrow$ (ii) Let $\mathrm{A}$ be a fuzzy number such that $[A]^{\gamma}=\left[a_{1}(\gamma), a_{2}(\gamma)\right]$ for $\gamma \in[0,1]$. Since $\mathrm{u}$ is concave, the following inequality holds:

$$
\frac{u\left(a_{1}(\gamma)\right)+u\left(a_{2}(\gamma)\right)}{2} \leq u\left(\frac{a_{1}(\gamma)+a_{2}(\gamma)}{2}\right)
$$

Taking into account that $\mathrm{f} \geq 0$ and applying Jensen inequality it follows:

$$
\begin{aligned}
& E(f, u(A))=\int_{0}^{1} \frac{u\left(a_{1}(\gamma)\right)+u\left(a_{2}(\gamma)\right)}{2} f(\gamma) d \gamma \leq \\
& \leq \int_{0}^{1} u\left(\frac{a_{1}(\gamma)+a_{2}(\gamma)}{2}\right) f(\gamma) d \gamma \\
& \leq u\left(\int_{0}^{1} \frac{a_{1}(\gamma)+a_{2}(\gamma)}{2} f(\gamma) d \gamma\right)=u(E(f, A))
\end{aligned}
$$

(ii) $\Rightarrow$ (i) Let a, $\mathrm{b} \in \mathbf{R}, \mathrm{a}<\mathrm{b}$. We consider the fuzzy number $\mathrm{A}$ for which $a_{1}(\gamma)=a$ and $a_{2}(\gamma)=b$ for any $\gamma \in[0,1]$. Then $E(f, u(A))=\frac{u(a)+u(b)}{2}$ and $u(E(f, A))=u\left(\frac{a+b}{2}\right)$.

By hypothesis, we will have $\frac{u(a)+u(b)}{2} \leq u\left(\frac{a+b}{2}\right)$.

This inequality holds for any $\mathrm{a}, \mathrm{b} \in \mathbf{R}$ and $\mathrm{u}$ is continuous. By Lemma 1 , it follows that $\mathrm{u}$ is concave.

Corollary 1 . If $\mathrm{u}$ is a continuous utility function then the following are equivalent:

a) $\mathrm{u}$ is convex;

b) $u(E(f, A)) \leq E(f, u(A))$ for any fuzzy number $A$.

The following result appears implicitly in the proof of Proposition 4.4.2 of [7].

Proposition 3. If u is a utility function of class $C^{2}$ then:

$$
E(f, u(A)) \approx u(E(f, A))+\frac{1}{2} u^{\prime \prime}(E(f, A)) \operatorname{Var}(f, A)
$$

\section{A PossibILISTIC MODEL OF PRECAUTIONARY SAVING}

In this section we define a notion of precautionary saving in the framework of an optimal saving possibilistic model. The positivity of precautionary saving shows that the presence of risk increases the level of optimal saving. Intuitively this points out that the agent is "prudent" in the face of possibilistic risk. The main result of the section characterizes this "prudence in an intuitive sense" by the positivity of the third derivative of one of consumer's utility functions. 
The probabilistic two-period model of precautionary saving from [6], p. 65 is characterized by the following data:

- $\mathrm{u}(\mathrm{y})$ and $\mathrm{v}(\mathrm{y})$ are the utility functions of the consumer for period 0 , resp. 1

- for period 0 there exists a sure income $y_{0}$ and for period 1 an uncertain income given by a random variable $\tilde{y}$

- $\mathrm{x}$ is the level of saving for period 0

Assume that $\mathrm{u}, \mathrm{v}$ have the class $C^{2}$ and $u^{\prime}>0, v^{\prime}>0$, $u^{\prime \prime}<0, v^{\prime \prime}<0$. The expected lifetime utility of the model is:

$$
V(s)=u\left(y_{0}-s\right)+M(v((1+r) s+\tilde{y}))
$$

where $r$ is the rate of interest for saving.

The consumer's problem is to choose that value of $\mathrm{s}$ for which the maximum of $\mathrm{V}(\mathrm{s})$ is attained.

The possibilistic model of optimal saving that we are going to build further starts from the same data, except for the fact that $\tilde{y}$ will be replaced by a fuzzy number.

We fix a weighting function $\mathrm{f}$ and a fuzzy number $\mathrm{A}$ whose level sets are $[A]^{\gamma}=\left[a_{1}(\gamma), a_{2}(\gamma)\right]$ for $\gamma \in[0,1]$.

The (possibilistic) expected lifetime utility $\mathrm{W}(\mathrm{s})$ of our model will be defined using the notions of possibilistic expected utility from the previous section.

$W(s)=u\left(y_{0}-s\right)+E(f, v((1+r) s+A))$

The relation (5) can be written:

$$
\begin{aligned}
& W(s)=u\left(y_{0}-s\right)+\frac{1}{2} \int_{0}^{1}\left[v\left((1+r) s+a_{1}(\gamma)\right)+\right. \\
& \left.+v\left((1+r) s+a_{2}(\gamma)\right)\right] f(\gamma) d \gamma
\end{aligned}
$$

By derivation, from (6) one obtains:

$$
\begin{aligned}
& W^{\prime}(s)=-u^{\prime}\left(y_{0}-s\right)+\frac{1+r}{2} \int_{0}^{1}\left[v^{\prime}\left((1+r) s+a_{1}(\gamma)\right)+\right. \\
& \left.+v^{\prime}\left((1+r) s+a_{2}(\gamma)\right)\right] f(\gamma) d \gamma
\end{aligned}
$$

which can be written:

$W^{\prime}(s)=-u^{\prime}\left(y_{0}-s\right)+(1+r) E\left(f, v^{\prime}((1+r) s+A)\right)(8)$

Deriving it one more time it follows

$$
W^{\prime \prime}(s)=u^{\prime \prime}\left(y_{0}-s\right)+\frac{(1+r)^{2}}{2} \int_{0}^{1}\left[v^{\prime \prime}\left((1+r) s+a_{1}(\gamma)\right)\right.
$$$$
\left.+v^{\prime \prime}\left((1+r) s+a_{2}(\gamma)\right)\right] f(\gamma) d \gamma
$$

One considers the following optimization problem:

$$
\max _{s} W(s)
$$

Proposition 4. (i) $\mathrm{W}$ is a strictly concave function.

(ii) The optimal solution $s^{*}=s^{*}(A)$ of problem (10) is given by $W^{\prime}\left(s^{*}\right)=0$.

Proof. (i) By hypothesis, $u^{\prime \prime}<0, v^{\prime \prime}<0$, thus by (9) it follows $W^{\prime \prime}(s)<0$ for any $s \in \mathbf{R}$. (ii) follows from (i).

By Proposition 4 (ii) and (8), it follows that the optimal solution $s^{*}$ is determined by the following equality:

$$
u^{\prime}\left(y_{0}-s^{*}\right)=(1+r) E\left(f, v^{\prime}\left((1+r) s^{*}+A\right)\right)
$$

Let $\mathrm{h}: \mathbf{R} \rightarrow \mathbf{R}$ be a function of class $C^{2}$. If $\mathrm{A}$ is a fuzzy number then we denote

$$
\Gamma_{A}(h)=h(E(f, A))+\frac{h^{\prime}(E(f, A))}{2} \operatorname{Var}(f, A)
$$

Proposition 5. The optimal solution $s^{*}$ of problem (10) has the approximate value:

$$
s^{*} \approx \frac{u^{\prime}\left(y_{0}\right)-(1+r) \Gamma_{A}\left(v^{\prime}\right)}{u^{\prime \prime}\left(y_{0}\right)+(1+r)^{2} \Gamma_{A}\left(v^{\prime \prime}\right)}
$$

Proof. Applying the first order Taylor formula one has:

$$
u^{\prime}\left(y_{0}-s^{*}\right) \approx u^{\prime}\left(y_{0}\right)-s^{*} u^{\prime \prime}\left(y_{0}\right)
$$

By Proposition 3

$$
\begin{aligned}
& E\left(f, v^{\prime}\left((1+r) s^{*}+A\right)\right) \approx v^{\prime}\left((1+r) s^{*}+E(f, A)\right)+ \\
& +\frac{1}{2} v^{\prime \prime}\left((1+r) s^{*}+E(f, A)\right) \operatorname{Var}(f, A)
\end{aligned}
$$

Applying again the first order Taylor formula it follows $v^{\prime}\left((1+r) s^{*}+E(f, A)\right) \approx v^{\prime}(E(f, A))+(1+r) s^{*} v^{\prime \prime}(E(f, A))$ $v^{\prime \prime}\left((1+r) s^{*}+E(f, A)\right) \approx v^{\prime \prime}(E(f, A))+(1+r) s^{*} v^{\prime \prime \prime}(E(f, A))$

Replacing in (13) it follows:

$E\left(f, v^{\prime}\left((1+r) s^{*}+A\right)\right) \approx v^{\prime}(E(f, A))+$

$+(1+r) s^{*} v^{\prime \prime}(E(f, A))+\frac{1}{2}\left[v^{\prime \prime}(E(f, A))+\right.$

$\left.+(1+r) s^{*} v^{\prime \prime \prime}(E(f, A))\right] \operatorname{Var}(f, A)=$

$=\left[v^{\prime}(E(f, A))+\frac{v^{\prime \prime}(E(f, A))}{2} \operatorname{Var}(f, A)\right]+$

$+(1+r) s^{*}\left[v^{\prime \prime}(E(f, A))+\frac{v^{\prime \prime \prime}(E(f, A))}{2} \operatorname{Var}(f, A)\right]$

from where one obtains:

$E\left(f, v^{\prime}\left((1+r) s^{*}+A\right)\right) \approx$

$\approx \Gamma_{A}\left(v^{\prime}\right)+(1+r) s^{*} \Gamma_{A}\left(v^{\prime \prime}\right)$

From (11), (13), (14) we obtain

$u^{\prime}\left(y_{0}\right)-s^{*} u^{\prime \prime}\left(y_{0}\right) \approx(1+r) \Gamma_{A}\left(v^{\prime}\right)+(1+r)^{2} s^{*} \Gamma_{A}\left(v^{\prime \prime}\right)$

From where the following approximate value of $s^{*}$ follows:

$s^{*} \approx \frac{u^{\prime}\left(y_{0}\right)-(1+r) \Gamma_{A}\left(v^{\prime}\right)}{u^{\prime \prime}\left(y_{0}\right)+(1+r)^{2} \Gamma_{A}\left(v^{\prime \prime}\right)}$

We consider now the optimal saving model in which in period 1 we don't have uncertainty any more: the uncertain income $\mathrm{A}$ is replaced by the sure income $\mathrm{E}(\mathrm{f}, \mathrm{A})$. The lifetime utility of the model is:

$W_{1}(x)=u\left(y_{0}-s\right)+v((1+r) s+E(f, A))$ 
and the optimization problem becomes:

$$
\max _{s} W_{1}(s)=W_{1}\left(s_{1}^{*}\right)
$$

In this case one has

$W_{1}^{\prime}(s)=-u^{\prime}\left(y_{0}-s\right)+(1+r) v^{\prime}((1+r) s+E(f, A))(17)$

The optimal solution $s_{1}^{*}=s_{1}^{*}(E(f, A))$ of problem (16) is given by $W_{1}^{\prime}\left(s^{*}\right)=0$, which, by (17), is written:

$$
u^{\prime}\left(y_{0}-s_{1}^{*}\right)=(1+r) v^{\prime}\left((1+r) s_{1}^{*}+E(f, A)\right)(18)
$$

The difference $s^{*}-s_{1}^{*}$ will be called possibilistic precautionary saving (associated with $y_{0}, \mathrm{r}$ and A). This indicator measures the way the presence of the possibilistic risk A causes changes in consumer's decision to establish the optimal saving.

The following proposition is the main result on our optimal saving model. The key-element of its proof is the application of Proposition 2.

Proposition 6. The following assertions are equivalent:

(i) $s^{*}(A)-s_{1}^{*}(A) \geq 0$ for any fuzzy number $\mathrm{A}$;

(ii) $v^{\prime \prime \prime}(x) \geq 0$ for any $\mathrm{x} \in \mathbf{R}$.

Proof. Let A be a fuzzy number. From (17) and (11) one obtains, by denoting $s^{*}=s^{*}(A)$ :

$$
\begin{aligned}
& W_{1}^{\prime}\left(s^{*}\right)=-u^{\prime}\left(y_{0}-s^{*}\right)+(1+r) v^{\prime}\left((1+r) s^{*}+E(f, A)\right) \\
& =(1+r)\left[v^{\prime}\left((1+r) s^{*}+E(f, A)\right)-\right. \\
& \left.-E\left(f, v^{\prime}\left((1+r) s^{*}+A\right)\right)\right]
\end{aligned}
$$

Since $W_{1}^{\prime}$ is a strictly decreasing function one has

$$
\begin{aligned}
& s^{*}(A) \geq s_{1}^{*}(A) \text { iff } \\
& W_{1}^{\prime}\left(s^{*}(A)\right) \leq W_{1}^{\prime}\left(s_{1}^{*}(A)\right)=0
\end{aligned}
$$

Taking into account the value of $W_{1}^{\prime}\left(s^{*}\right)$ computed above one obtains:

$$
s^{*}(A) \geq s_{1}^{*}(A)
$$

iff

$$
v^{\prime}\left(E\left(f,(1+r) s^{*}(A)+A\right)\right) \leq E\left(f, v^{\prime}\left((1+r) s^{*}(A)+A\right)\right)
$$

The previous inequality holds for any fuzzy number A, thus, by Corollary 1, the following equivalences follow:

- $s^{*}(A) \geq s_{1}^{*}(A)$ for any fuzzy number $\mathrm{A}$

- $v^{\prime}$ is convex

- $v^{\prime \prime \prime}(x) \geq 0$ for any $\mathrm{x} \in \mathbf{R}$.

Condition (i) of Proposition 6 (=the positivity of possibilistic precautionary saving) expresses the fact that the presence of risk leads to the increase of optimal saving, and condition (ii) is the well-known property of "prudence" introduced by Kimball in [4]. Since condition (ii) is present both in Kimball's result and in Proposition 6, we conclude that the positivity of possibilistic precautionary saving is equivalent with the positivity of probabilistic precautionary saving.

Example 1. We consider the possibilistic optimal saving model with the following utility functions:

$u(y)=v(y)=-e^{-y}$ for $\mathrm{y} \in \mathbf{R}$.

We remark that $u^{\prime}(y)=v^{\prime}(y)=e^{-y}$, $u^{\prime \prime}(y)=v^{\prime \prime}(y)=-e^{-y}$ for any $\mathrm{y} \in \mathbf{R}$.

Let $\mathrm{A}$ be a fuzzy number and $\mathrm{f}$ a weighting function. Then

$$
\begin{aligned}
& \Gamma_{A}\left(v^{\prime}\right)=e^{-E(f, A)}-\frac{1}{2} e^{-E(f, A)} \operatorname{Var}(f, A) \\
& \Gamma_{A}\left(v^{\prime \prime}\right)=-e^{-E(f, A)}+\frac{1}{2} e^{-E(f, A)} \operatorname{Var}(f, A)
\end{aligned}
$$

By Proposition 5, the optimal solution of problem (10) will have the approximate value:

$$
\begin{aligned}
s^{*} \approx & \frac{u^{\prime}\left(y_{0}\right)-(1+r) \Gamma_{A}\left(v^{\prime}\right)}{u^{\prime \prime}\left(y_{0}\right)+(1+r)^{2} \Gamma_{A}\left(v^{\prime \prime}\right)} \\
= & \frac{e^{-y_{0}}-(1+r) e^{-E(f, A)}\left[1-\frac{1}{2} \operatorname{Var}(f, A)\right]}{-e^{-y_{0}}+(1+r)^{2} e^{-E(f, A)}\left[-1+\frac{1}{2} \operatorname{Var}(f, A)\right]}
\end{aligned}
$$

The approximate value of $s^{*}$ can be written:

$$
s^{*} \approx-\frac{1-(1+r) \theta\left(y_{0}, A\right)}{1+(1+r)^{2} \theta\left(y_{0}, A\right)}
$$

where

$$
\theta\left(y_{0}, A\right)=e^{y_{0}-E(f, A)}\left[1-\frac{1}{2} \operatorname{Var}(f, A)\right]
$$

If we replace $\mathrm{A}$ with the fuzzy point $\mathrm{E}(\mathrm{f}, \mathrm{A})$ it follows:

$$
\theta\left(y_{0}, E(f, A)\right)=e^{y_{0}-E(f, A)}
$$

since $\operatorname{Var}(f, E(f, A))=0$. In this case we obtain an approximate value of the optimal solution of problem (10):

$$
\begin{aligned}
& s_{1}^{*} \approx-\frac{1-(1+r) \theta\left(y_{0}, E(f, A)\right)}{1+(1+r)^{2} \theta\left(y_{0}, E(f, A)\right)} \\
& =-\frac{1-(1+r) e^{y_{0}-E(f, A)}}{1+(1+r)^{2} e^{y_{0}-E(f, A)}}
\end{aligned}
$$

\section{POSSIBILISTIC PRUDENCE}

In this section we will define the meaning that an agent is prudent in the face of risk modeled by a fuzzy number. This definition is inspired by the concept of prudence in possibilistic sense as it has been defined in [12], [11]. Using the results from the previous section we will find an equivalent formulation of possibilistic prudence in terms of precautionary saving.

Consider an agent with the utility function u of class $C^{2}$ with $u^{\prime}>0, u^{\prime \prime}<0$ and $\mathrm{f}$ a weighting function. If $\mathrm{X}$ is a random variable then $M(X)$ is its expected value and $M(u(X))$ is the expected utility associated with $\mathrm{u}$ and $\mathrm{X}$. 
The probabilistic utility premium $\mathrm{w}(\mathrm{x}, \mathrm{X}, \mathrm{u})$ associated with the real number $\mathrm{x}$, the random variable $\mathrm{X}$ and $\mathrm{u}$ was introduced by Friedman and Savage in [16]:

$$
w(x, X, u)=u(x)-M(u(x+X))
$$

By [17], the probabilistic utility premium $w(x, X, u)$ measures "the degree of pain associated with facing the risk $\mathrm{X}$, where pain is measured by the loss in the expected utility from adding the risk $\mathrm{X}$ to wealth $\mathrm{X}^{\prime \prime}$.

Similarly, we will define the possibilistic utility premium $\mathrm{w}(\mathrm{x}, \mathrm{A}, \mathrm{u})$ associated with $\mathrm{x} \in \mathbf{R}$, the fuzzy number $\mathrm{A}$ and the utility function $\mathrm{u}$ by

$$
w(x, A, u)=u(x)-E(f, u(x+X))
$$

Assume that the level sets of the fuzzy number $A$ are $[A]^{\gamma}=\left[a_{1}(\gamma), a_{2}(\gamma)\right]$ for any $\gamma \in[0,1]$. Then $(20)$ is written:

$$
\begin{aligned}
& w(x, A, u)=u(x)-\frac{1}{2} \int_{0}^{1} u\left(x+a_{1}(\gamma)\right)+ \\
& \left.+u\left(x+a_{2}(\gamma)\right)\right] f(\gamma) d \gamma
\end{aligned}
$$

We recall from [11], [12] what means that the agent is probabilistically prudent.

Let $\mathrm{x}$ be the initial wealth, $\mathrm{k}$ a positive constant and $\mathrm{X}$ a random variable with $\mathrm{M}(\mathrm{X})=0$. We denote

$$
\begin{aligned}
& S(x, k, X, u)=u(x-k)+M(u(x+X))-u(x)- \\
& -M(u(x-k+X))
\end{aligned}
$$

One notices that $S(x, k, X, u)=w(x-k, X, u)$ -

$$
-w(x, X, u)
$$

$S(x, k, X, u)$ is called in [17] the prudence utility premium and it is interpreted as measuring "the increase in pain of facing the risk $\mathrm{X}$ in the presence of a sure loss $\mathrm{k}>0$ ".

By [11], [12], we say that the agent $\mathrm{u}$ is probabilistically prudent if $S(x, k, X, u) \geq 0$ for any triple (x,k,X) as above.

The above discussion is the starting point in defining the possibilistic prudence.

If $x$ is the initial wealth, $k$ a positive constant and $A$ a fuzzy number with $\mathrm{E}(\mathrm{f}, \mathrm{A})=0$ then we denote

$$
\begin{aligned}
& S(x, k, A, u)=u(x-k)+E(f, u(x+A))-u(x)- \\
& -E(f, u(x-k+A))
\end{aligned}
$$

$S(x, k, A, u)$ will be called the possibilistic prudence utility premium. It has a similar interpretation with the probabilistic prudence utility premium $S(x, k, X, u)$, but we have the possibilistic risk A instead of probabilistic risk $\mathrm{X}$.

One sees immediately that

$$
S(x, k, A, u)=w(x-k, A, u)-w(x, A, u)
$$

Definition 1 . The agent $\mathrm{u}$ is possibilistically prudent if

$S(x, k, A, u) \geq 0$ for any triple $(\mathrm{x}, \mathrm{k}, \mathrm{A})$ with the above significance.

Remark 1. According to (24), the agent is possibilistically prudent iff the possibilistic utility premium $\mathrm{w}(\mathrm{x}, \mathrm{A}, \mathrm{u})$ is decreasing in $\mathrm{x}$.

Proposition 7. Assume that the utility function $u$ has the class $C^{3}$ and $u^{\prime}>0, \quad u^{\prime \prime}<0$. Then the following are equivalent;

(i)The agent $\mathrm{u}$ is possibilistically prudent;

(ii) $u^{\prime \prime \prime}(x) \geq 0$ for any $\mathrm{x} \in \mathbf{R}$.

Proof. Deriving (21) w.r.t. $x$ we obtain

$$
\begin{aligned}
& w^{\prime}(x, A, u)=u^{\prime}(x)-\frac{1}{2} \int_{0}^{1}\left[u^{\prime}\left(x+a_{1}(\gamma)\right)+\right. \\
& \left.+u^{\prime}\left(x+a_{2}(\gamma)\right)\right] f(\gamma) d \gamma \\
& =u^{\prime}(x)-E\left(f, u^{\prime}(x+A)\right)
\end{aligned}
$$

From the previous inequality and taking into account Remark 1 and Corollary 1 the equivalence of the following assertions follows:

-the agent $\mathrm{u}$ is possibilistically prudent

- $w^{\prime}(x, A, u) \leq 0$ for all $\mathrm{x}$ and $\mathrm{A}$

- $u^{\prime}(x) \leq E\left(f, u^{\prime}(x+A)\right)$ for all $\mathrm{x}$ and $\mathrm{A}$

- $u^{\prime}(E(f, x+A)) \leq E\left(f, u^{\prime}(x+A)\right)$ for all $\mathrm{x}$ and $\mathrm{A}$

- $u^{\prime}$ is convex

- $u^{\prime \prime \prime} \geq 0$

We go back now to the possibilistic precautionary saving model from Section $3(\mathrm{u}(\mathrm{y})$ and $\mathrm{v}(\mathrm{y})$ are the utility functions of the consumer for period 0 , resp. 1).

Theorem 1. Under the conditions of Section 3 the following assertions are equivalent:

(a) $s^{*}(A)-s_{1}^{*}(A) \geq 0$ for any fuzzy number $\mathrm{A}$

(b) $v^{\prime \prime \prime}(x) \geq 0$ for any $\mathrm{x} \in \mathbf{R}$

(c) The agent $v$ is possibilistically prudent.

Proof. $(a) \Leftrightarrow(b)$ By Proposition 6 .

(b) $\Leftrightarrow$ (c ) By Proposition 7.

Remark 2. The above theorem provides a more intuitive meaning to the notion of possibilistic prudence formally introduced by Definition 1 . Indeed, by the equivalence $(a) \Leftrightarrow$ (c) it follows that the agent $\mathrm{v}$ is possibilistically prudent iff in the presence of risk he chooses a higher level of optimal saving.

Remark 3. In the optimal saving model of Section 3, the consumer is represented by the pair of utility functions $(\mathrm{u}, \mathrm{v})$. As the risk may appear only in period 1 (when the consumer 's behavior is described by $v)$, the prudence of consumer $(\mathrm{u}, \mathrm{v})$ in the face of risk coincides with v's prudence in the face of risk. Therefore, under condition (c ) of Theorem 1, we deal with the prudence of consumer $(\mathrm{u}, \mathrm{v})$.

\section{PRUdENCE AND POSSIBILISTIC RISK AVERSION}

Following the line of Kimball from [4], in this section we will investigate the relation between prudence and possibilistic risk aversion, issue treated in [7]. Both topics describe two attitudes of an agent in the face of risk. By defining possibilistic precautionary premium as a case of possibilistic 
risk premium [7], the results of the theory of possibilistic risk aversion are transferred to possibilistic prudence.

We consider an agent with the utility function $\mathrm{u}$ of class $C^{2}$ and $u^{\prime}>0, u^{\prime \prime}<0$. The Arrow-Pratt index $r_{u}$ is defined by [13], [14]:

$$
r_{u}(x)=-\frac{u^{\prime \prime}(x)}{u^{\prime}(x)}, \mathrm{x} \in \mathbf{R} .
$$

If $\mathrm{u}$ has the class $C^{3}$ then the degree of absolute prudence $P_{u}$ was defined by Kimball in [4]:

$$
P_{u}(x)=-\frac{u^{\prime \prime \prime}(x)}{u^{\prime \prime}(x)}, \mathrm{x} \in \mathbf{R} .
$$

One notices that $P_{u} \geq 0$ iff $u^{\prime \prime \prime} \geq 0$. If $g=-u^{\prime}$ then $P_{u}=r_{g}$.

In the above mentioned papers, $r_{u}$ and $P_{u}$ are indicators for analyzing probabilistic risk.

$r_{u}$ is a measure of risk aversion and $P_{u}$ is a measure of the agent's prudence in the face of risk. By [7], the Arrow-Pratt index is an efficient instrument for the study of risk represented by fuzzy numbers.

We fix a weighting function $\mathrm{f}$, a utility function $\mathrm{u}$, a fuzzy number $\mathrm{A}$ and a real number $\mathrm{x}$. $\mathrm{u}$ represents the agent, $\mathrm{A}$ the risk situation and $\mathrm{x}$ is the wealth. We define the possibilistic risk premium $\pi(x, A, u)$ as the unique solution of the equation:

$$
E(f, u(x+A))=u(x+E(f, A)-\pi(x, A, u))
$$

In interpretation, the bigger $\pi(x, A, u)$ is, the bigger the agent's risk aversion is.

\section{Proposition 8. [7]}

$$
\pi(x, A, u) \approx \frac{1}{2} r_{u}(x+E(f, A)) \operatorname{Var}(f, A)
$$

Let $u_{1}, u_{2}$ be the utility functions of two agents such that $u_{1}^{\prime}>0, u_{2}^{\prime}>0, u_{1}^{\prime \prime}<0, u_{2}^{\prime \prime}<0$. We denote $r_{1}=r_{u_{1}}$, $r_{2}=r_{u_{2}}$.

Proposition 9. [7] The following assertions are equivalent:

(a) $r_{1}(x) \geq r_{2}(x)$ for any $\mathrm{x} \in \mathbf{R}$;

(b) For any $x \in \mathbf{R}$ and for any fuzzy number $\mathrm{A}$, $\pi\left(x, A, u_{1}\right) \geq \pi\left(x, A, u_{2}\right)$.

The above result is the possibilistic analogue of Pratt theorem [14]. It shows how using the Arrow-Pratt index one can compare the aversions to possibilistic risk of the two agents.

The following proposition establishes a connection between the possibilistic risk aversion and prudence.

Proposition 10. The following assertions are equivalent:

(i) For any fuzzy number $\mathrm{A}$, the possibilistic risk premium $\pi(x, A, u)$ is decreasing in wealth: $x_{1} \leq x_{2}$ implies $\pi\left(x_{2}, A, u\right) \leq \pi\left(x_{1}, A, u\right)$;

(ii) For all $\mathrm{x} \in \mathbf{R}, P_{u}(x) \geq r_{u}(x)$ (prudence is larger than risk aversion).

Proof. Let A be a fuzzy number with $[A]^{\gamma}=\left[a_{1}(\gamma), a_{2}(\gamma)\right], \gamma \in[0,1]$. From (27) it follows:

$$
\begin{aligned}
& u(x+E(f, A)-\pi(x, A, u))= \\
& =\frac{1}{2} \int_{0}^{1}\left[u\left(x+a_{1}(\gamma)\right)+u\left(x+a_{2}(\gamma)\right)\right] f(\gamma) d \gamma
\end{aligned}
$$

Deriving and applying again (27) for $g=-u^{\prime}$ one obtains:

$$
\begin{aligned}
& \left(1-\pi^{\prime}(x, A, u)\right) u^{\prime}(x+E(f, A)-\pi(x, A, u))= \\
& =-\frac{1}{2} \int_{0}^{1}\left[g\left(x+a_{1}(\gamma)\right)+g\left(x+a_{2}(\gamma)\right)\right] f(\gamma) d \gamma= \\
& =-E(f, g(x+A)) \\
& =-g(x+E(f, A)-\pi(x, A, g))
\end{aligned}
$$

From these equalities it follows:

$$
\pi^{\prime}(x, A, u)=
$$

$\frac{g(x+E(f, A)-\pi(x, A, g))-g(x+E(f, A)-\pi(x, A, u)}{u^{\prime}(x+E(f, A)-\pi(x, A, u))}$

By hypothesis, $u^{\prime}>0$ and $\mathrm{g}$ is strictly increasing, thus the following assertions are equivalent:

- $\pi(x, A, u)$ is decreasing in $\mathrm{x}$

- For all $\mathrm{x}, \pi^{\prime}(x, A, u) \leq 0$

- For all $\mathrm{x}, g(x+E(f, A)-\pi(x, A, g)) \leq$

$\leq g(x+E(f, A)-\pi(x, A, u))$

- For all $\mathrm{x}, \pi(x, A, g) \geq \pi(x, A, u)$

By these equivalences and Proposition 9, the following assertions are equivalent:

- For any fuzzy number $\mathrm{A}, \pi(x, A, u)$ is decreasing in $\mathrm{x}$

-For any fuzzy number $\mathrm{A}$ and $\mathrm{x} \in \mathbf{R}$, $\pi(x, A, g) \geq \pi(x, A, u)$

- For any $\mathrm{x} \in \mathbf{R}, r_{g}(x) \geq r_{u}(x)$

Since $P_{u}(x)=r_{g}(x)$, the equivalence of assertions (i) and (ii) follows.

The (probabilistic) precautionary premium was introduced in [4] as "a measure of the strength of precautionary saving motive". We define now a similar notion in a possibilistic context.

Let $\mathrm{v}$ be a utility function of class $C^{3}$ with $v^{\prime}>0$, $v^{\prime \prime}<0$ and $v^{\prime \prime \prime}>0$. The possibilistic precautionary premium $\phi(x, A, v)$ associated with wealth $\mathrm{x}$, a fuzzy number $\mathrm{A}$ representing the risk and the utility function $\mathrm{v}$ is the unique solution of the equation:

$$
E\left(f, v^{\prime}(x+A)\right)=v^{\prime}(x+E(f, A)-\phi(x, A, v))(28)
$$

We returned to the model of precautionary saving of Section 
3 , assuming that $\mathrm{v}$ has the class $C^{3}$ and $v^{\prime}>0, v^{\prime \prime}<0$, $v^{\prime \prime \prime}>0$. By the optimum condition (11) of Section 3 and equation (28), it follows:

$$
\begin{aligned}
& u^{\prime}\left(y_{0}-s^{*}\right)= \\
& =(1+r) E\left(f, v^{\prime}\left((1+r) s^{*}+A\right)\right) \\
& =(1+r) v^{\prime}\left((1+r) s^{*}+E(f, A)-\phi\left((1+r) s^{*}, A, v\right)\right)
\end{aligned}
$$

We consider the case $\mathrm{r}=0$ and $\mathrm{u}=\mathrm{v}$. Then

$$
u^{\prime}\left(y_{0}-s^{*}\right)=u^{\prime}\left(s^{*}+E(f, A)-\phi\left(s^{*}, A, v\right)\right)
$$

from where, taking into account that $u^{\prime}$ is injective, it follows:

$$
s^{*}=\frac{1}{2}\left(y_{0}+\phi\left(s^{*}, A, v\right)-E(f, A)\right)
$$

Remark 4. The results of Section 4 connect possibilistic prudence and possibilistic precautionary saving. The size of a consumer's prudence is evaluated by the level of optimal saving $s^{*}$ : the bigger $s^{*}$ is, the more prudent the consumer is. Relation (29) between $s^{*}$ and $\phi\left(s^{*}, A, v\right)$ shows that the possibilistic precautionary premium is an indicator of the agent's prudence.

One notices that $\phi(x, A, v)=\pi\left(x, A,-v^{\prime}\right)$ therefore we can apply to $\phi(x, A, v)$ all the results valid for possibilistic risk premium. In particular, Propositions 8, 9, 10 lead to

\section{Proposition 11.}

$$
\phi(x, A, v) \approx \frac{1}{2} P_{v}(x+E(f, A)) \operatorname{Var}(f, A)
$$

Proposition 12. Let $v_{1}, v_{2}$ be two utility functions of class $C^{3}$ with $v_{1}^{\prime}>0, \quad v_{2}^{\prime}>0, \quad v_{1}^{\prime \prime}<0, \quad v_{2}^{\prime \prime}<0, \quad v_{1}^{\prime \prime \prime}>0$, $v_{2}^{\prime \prime \prime}>0$. The following assertions are equivalent:

(a) $P_{v_{1}}(x) \geq P_{v_{2}}(x)$ for any $\mathrm{x} \in \mathbf{R}$

(b) For any $\mathrm{x} \in \mathbf{R}$ and for any fuzzy number $\mathrm{A}$,

$$
\phi\left(x, A, v_{1}\right) \geq \phi\left(x, A, v_{2}\right)
$$

Proposition 13. Let v be a utility function of class $C^{4}$ with $v^{\prime}>0, v^{\prime \prime}<0, v^{\prime \prime \prime}>0, v^{i v}<0$. The following assertions are equivalent:

(i) For any fuzzy number $\mathrm{A}$, the possibilistic precautionary premium $\phi(x, A, v)$ is decreasing in $\mathrm{x}$;

$$
\text { (ii) }-\frac{v^{i v}(x)}{v^{\prime \prime \prime}(x)} \geq-\frac{v^{\prime \prime \prime}(x)}{v^{\prime \prime}(x)} \text { for any } \mathrm{x} \in \mathbf{R} \text {. }
$$

The three propositions from above are possibilistic versions of theorems of Kimball [4]. Proposition 11 provides an approximate calculation formula of possibilistic precautionary premium w.r.t. the index of absolute prudence and the possibilistic indicators associated with a fuzzy number A. The equivalence of conditions (a), (b) of Proposition 12 gives a criterion to compare the prudence of the agents represented by the utility functions $v_{1}, v_{2}$. By [12], $-\frac{v^{i v}(x)}{v^{\prime \prime \prime}(x)}$ is called the degree of temperance of the utility function $\mathrm{v}$. As $-\frac{v^{\prime \prime \prime}(x)}{v^{\prime \prime}(x)}$ is the degree of absolute prudence of $\mathrm{v}$, the inequality of condition (ii) of Proposition 13 expresses the fact that temperance is bigger than prudence.

\section{CONCLUSION}

The possibilistic approach of the optimal saving problem is founded on the hypothesis that risk situations are represented by fuzzy numbers, and consumers are described by their utility functions. The formulation of the possibilistic optimal saving problem and the definition of possibilistic prudence use the notion of possibilistic expected utility from [7]. The study of these two topics and their interconnections use the two main possibilistic indicators: expected value and variance [7], [9].

This paper contains the following contributions:

- The characterization of the concavity of continuous utility functions by a possibilistic Jensen-type inequality;

- The definition of the notion of possibilistic precautionary saving and the characterization of its prudence (i. e. the optimal saving increases in the presence of risk) by the condition of positivity of the third derivative of the utility function (= the prudence in the sense of Kimball [4]) ;

- The definition of the notion of possibilistic prudence (following the line of [11], [12]) and its characterization by the positivity of precautionary saving

- The relation between possibilistic risk aversion and prudence;

- The definition of possibilistic precautionary premium as "strength" of possibilistic precautionary saving, its approximate calculation and its use to compare the degrees of absolute prudence of two consumers.

We mention a few directions to continue the research of this paper:

- the study of a model of optimal saving and prudence in case of several risk parameters represented by fuzzy numbers;

- the study of optimal saving and prudence for situations with mixed risk parameters: ones represented by random variables, and others by fuzzy numbers;

- the possibilistic analysis of temperance and other higher-order risk attitudes of an agent [18].

\section{REFERENCES}

[1] H. Leland, "Saving and uncertainty: the precautionary demand for saving," Quarterly J. Economics, vol. 82, pp. 465-473, 1968.

[2] A. Sandmo, "The effect of uncertainty on saving decision," Rev. Economic Studies, vol. 37, pp. 353-360, 1970.

[3] J. Drèze and F. Modigliani, "Consumption decision under uncertainty," J. Economic Theory, vol. 5, pp. 308-355, 1972.

[4] M. S. Kimball, "Precautionary saving in the small and in the large," Econometrica, vol. 58, pp. 53-73, 1990. 
[5] L. A. Zadeh, "Fuzzy sets as a basis for a theory of possibility," Fuzzy Sets Syst., vol. 1, pp. 3-28, 1978.

[6] L. Eeckhoudt, C. Gollier and H. Schlesinger, Economic and Financial Decisions under Risk. Princeton University Press, 2005.

[7] I. Georgescu, Possibility Theory and the Risk. Springer, 2012.

[8] C. Carlsson and R. Fullér, "On possibilistic mean value and variance of fuzzy numbers, "Fuzzy Sets Syst., vol. 122, pp. 315-326, 2001.

[9] C. Carlsson and R. Fullér, Possibility for Decision. Springer, 2011.

[10] D. Dubois and H. Prade, Possibility Theory. New York: Plenum Press, 1988.

[11] D. Crainich and L. Eeckhoudt, "On the intensity of downside risk aversion," J. Risk Uncertainty, vol. 36, pp. 267-276, 2008.

[12] L. Eeckhoudt and H. Schlesinger, "Putting risk in its proper place," American Economic Review, vol. 96, pp. 280-289, 2006.

[13] K. J. Arrow, Essays in the Theory of Risk Bearing. Amsterdam: North Holland, 1970.

[14] J. Pratt, "Risk aversion in the small and in the large," Econometrica, vol. 32, pp. 122-130, 1964.

[15] W. Rudin, Analiză Normală şi Complexă, Ediţia a III-a, Bucharest: Editura Theta, 1999.

[16] M. Friedman and L. Savage, "The utility analysis of choices involving risk," J. Political Economy, vol. 56, pp. 279-304, 1948.

[17] C Courbage and B. Rey, "Precautionary saving in the presence of other risks," Economic Theory, vol. 32, pp. 417-424, 2007.

[18] L. Eeckhoudt and H. Schlesinger, "Higher-order risk attitudes," Handbook of Insurance, 2 January 2012 [Online]. Available: http://www.fox.temple.edu/cms/wp-

content/uploads/2012/06/Handbook-RiskAttitudes1.pdf

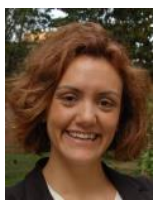

Ana María Lucia Casademunt is a professor of Business Administration at Faculty of Business Administration, University Loyola Andalucía, Cordoba, Spain. She has a Master Degree in Bank Economics and a Master Degree Master's degree in Organizational Psychology from University of Seville. Spain and a PhD in Business administration and Economics Sciences from University Loyola Andalucía. She has numerous publications in international leading journals.

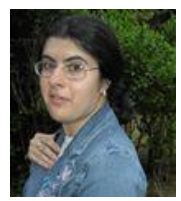

Irina Georgescu is with the Department of Computer Science and Economic Cybernetics, Academy of Economic Studies, Bucharest, Romania. She has a PhD in Economics from Turku Centre for Computer Science, Turku, Finland. She has published about 30 journal papers and 2 books in Springer Verlag. 